CASE REPORT

\title{
Basal Cell Carcinoma in Medial Canthal Region
}

\author{
Sunil Sidana ${ }^{1}$, Srivalli Natrajan ${ }^{2}$, Pradeep P Vathare ${ }^{3}$, Sneha Kadam ${ }^{4}$, Saloni B Shah ${ }^{5}$
}

\begin{abstract}
Background: Basal cell carcinoma (BCC) of the skin is the most common cancer, with a higher incidence than all other malignancies combined. Although it is rare to metastasize, patients with multiple or frequently recurring BCC can suffer substantial co-morbidity and be difficult to manage. The medial canthal region is a common site for tumors, particularly basal cell carcinoma.

Case description: Surgical approaches often offer the most effective and efficient. Medial canthal reconstruction following skin cancer excision presents a challenge to the surgeon because of the complex anatomy and the difficulty in obtaining tissue of the appropriate color and thickness. There are several options available for reconstruction of the medial canthal region including healing by secondary intention, full-thickness skin grafts, and local or regional flaps. Skin grafting can provide well contoured and esthetically acceptable results. Skin graft can be harvested from upper and lower eyelid, retro auricular, supraclavicular and preauricular region. We reconstructed medial canthal defect using graft from preauricular region as patient was old with enough lax skin and wrinkles on face.
\end{abstract}

Conclusion: Various skin graft techniques can be used for reconstruction of large superficial defects that involve medial canthal area. But preauricular skin graft is a useful technique that has good cosmesis and minimal postoperative complications.

Keywords: Basal cell carcinoma, Medial canthal region, Rodent ulcer.

Journal of Contemporary Dentistry (2019): 10.5005/jp-journals-10031-1271

\section{INTRODUCTION}

Basal cell carcinoma (BCC) is also termed rodent ulcer, basalioma, Jacob's ulcer, and basal cell epithelioma. About $75 \%$ of all skin cancers are basal cell carcinoma. ${ }^{1}$ The incidence of metastasis of BCC is very low. ${ }^{2}$ Risk factors for the growth of BCC includes physical features, such as green or blue eyes, light skin color, red or blond hair, exposures to arsenic, tar, coal, smoking, ionizing radiation, ultraviolet light, tanning-bed use, genodermatoses, like xeroderma pigmentosum, albinism, Gorlin's syndrome (Nevoid basal cell carcinoma syndrome), Rombo syndrome, Bazex Dupre Christol syndrome, immunosuppression includes recipients of solid organ transplants. ${ }^{3}$

Basal cell carcinomas are generally divided depending upon their variations in histological patterns. The histological patterns are superficial, morpheaform, nodular, pigmented, and micronodular. ${ }^{1}$ Nodular (60\%) and superficial (25\%) BCCs are usually referred to as nonaggressive types, while micronodular (15\%) and morpheaform (2\%). Basal cell carcinomas are usually considered as aggressive types, associated with a greater risk of local recurrence. ${ }^{4}$ BCCs of the head and neck region are more frequently seen in female (85.2\%) than in male $(81 \%)$, independent of their histological type. ${ }^{5}$

The medial canthus is a common site for BCCs. ${ }^{6}$ The medial canthal region represents the utmost challenging periorbital zone to reconstruct. The medial canthal region contains the bony attachments of the medial canthal tendon and the neurovascular structures and the lacrimal system. Conventionally, this region has been reconstructed using $\mathrm{V}-\mathrm{Y}$ advancement flaps, skin grafts, laterally based upper eyelid and cheek flaps, and glabellar flaps. ${ }^{7}$ A case of BCC of medial canthal region with preauricular skin graft was reported.

\section{Case Description}

A 52-year-old female reported to OMFS department, MGM Dental College and Hospital, with gradually increasing nodular growth

\footnotetext{
${ }^{1-5}$ Department of Oral and Maxillofacial Surgery, MGM Dental College and Hospital, Navi Mumbai, Maharashtra, India
}

Corresponding Author: Pradeep P Vathare, Department of Oral and Maxillofacial Surgery, MGM Dental College and Hospital, Navi Mumbai, Maharashtra, India, Phone: +91 9665585202,e-mail: vatharepradeep@ gmail.com

How to cite this article: Sidana S, Natrajan S, Vathare PP, et al. Basal Cell Carcinoma in Medial Canthal Region. J Contemp Dent 2019;9(3): 141-143.

Source of support: Nil

Conflict of interest: None

over medial canthal region since 10 years. Professionally, she was a street vegetable seller with increased hours in the sun.

On extraoral examination, $1 \times 1.5 \mathrm{~cm}$ irregular, brownish black, nodular growth was present over left medial canthus region. Punch biopsy confirmed it to be a nodular cystic BCC.

Under local anesthesia, lesion was excised with 5-mm margin. Medial canthus was left intact. Full-thickness skin graft was then harvested from the left preauricular region. The skin graft was defatted and sutured to the recipient site. A BIPP-impregnated Bolster (Figs 1 to 8).

\section{Discussion}

The aim of primary management of basal cell skin carcinoma is the cure of the tumor and the maximum preservation of function and esthetics. Surgical approaches usually offer the most effective and efficient means for accomplishing cure. ${ }^{8}$

The classification of BCC temples, periauricular region, nose, periorbital region, lip and angle of the jaw along with the hand, feet, and genitals are considered as "H zone" - areas with a high recurrence risk. The remaining face and scalp region along with the neck and pretibial region are considered as "M zone"-areas 


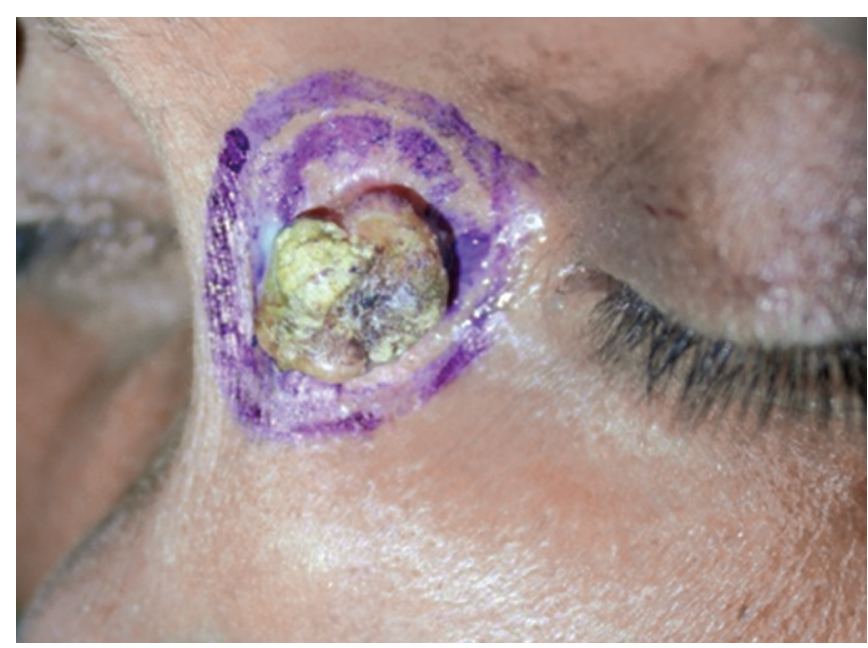

Fig. 1: Markings with a safety margin of $5 \mathrm{~mm}$

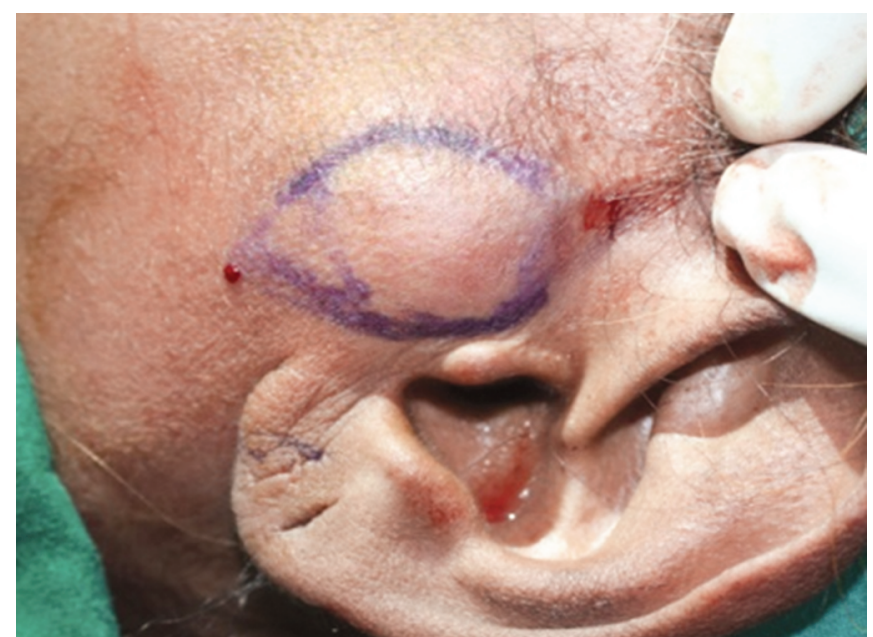

Fig. 3: Surgical defect transferred to donor site

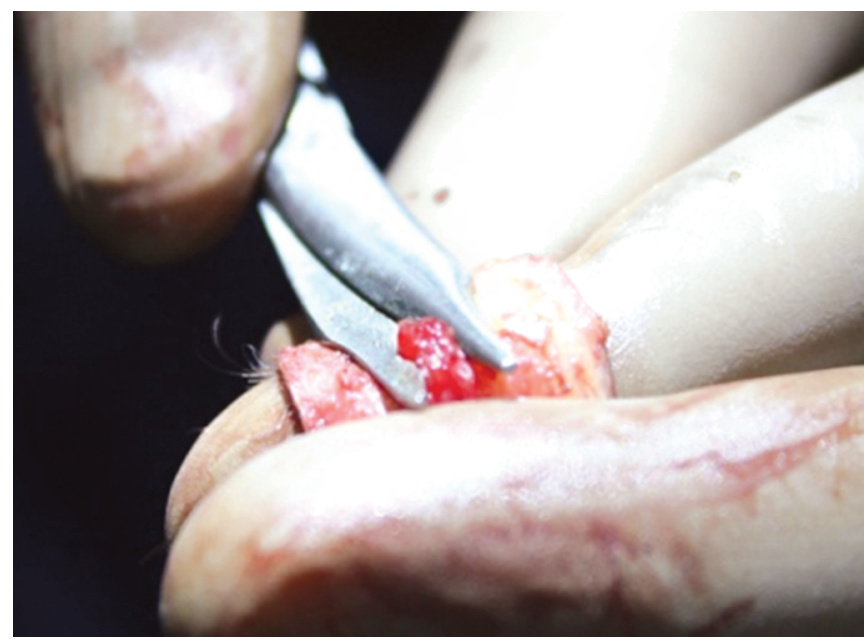

Fig. 5: Defatting of skin graft

with a moderate recurrence risk. The " $L$ zones" - areas with a low recurrence risk includes the trunk and extremities. ${ }^{5}$

The medial canthal region, $\mathrm{H}$ zone, represents one of the most challenging regions of the face to reconstruct due to the differences

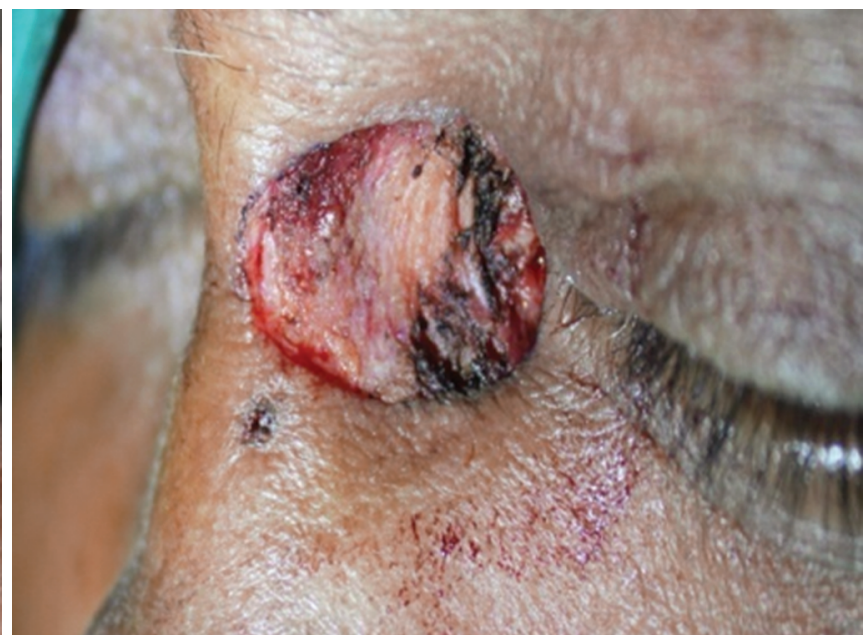

Fig. 2: Complete excision of lesion with clear margins

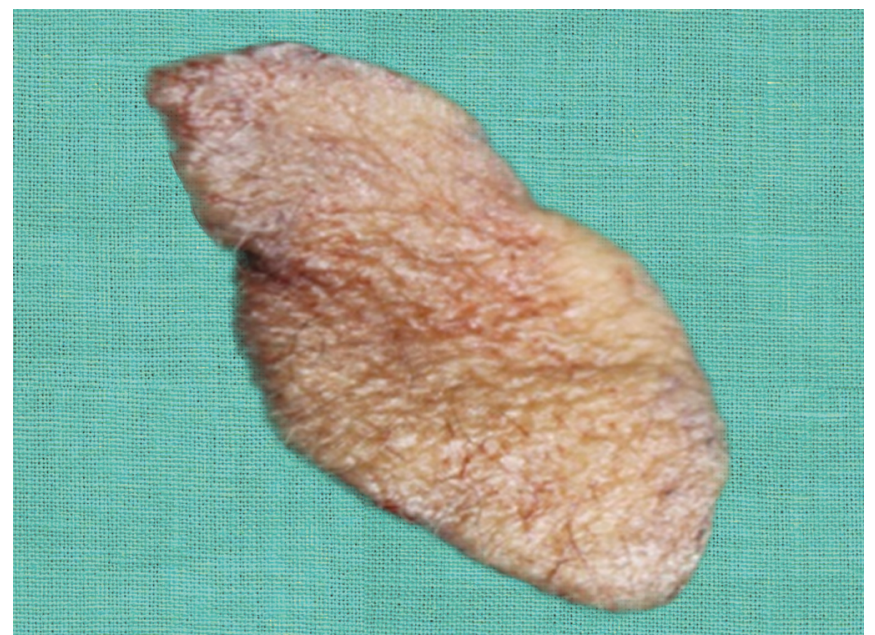

Fig. 4: Skin graft was harvested

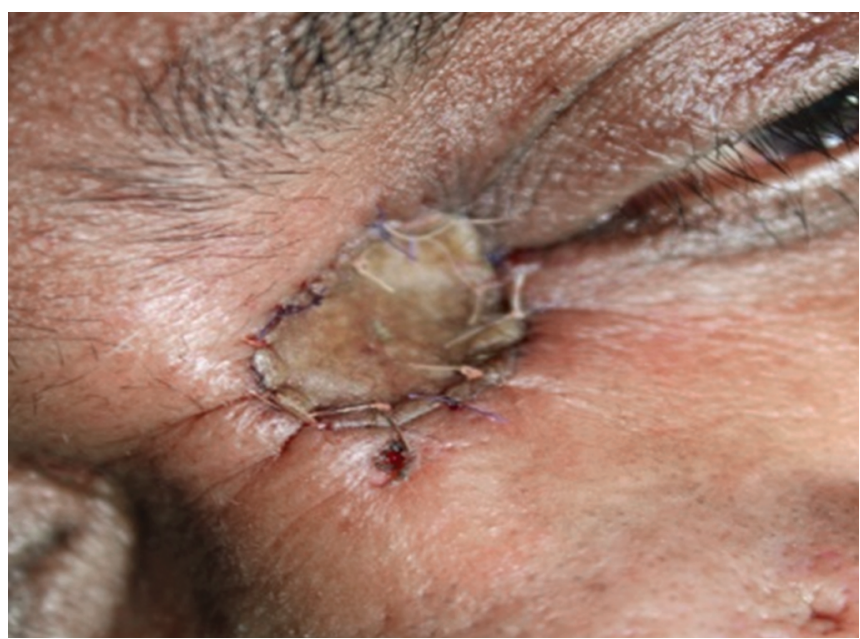

Fig. 6: Skin graft was sutured over defect without border tension

in skin texture, the concavity of the area, and the anatomical structures present. ${ }^{9}$ Defects in the medial canthal region requires reconstruction with the surrounding tissue so that it will have a normal shape and function. ${ }^{10}$ 


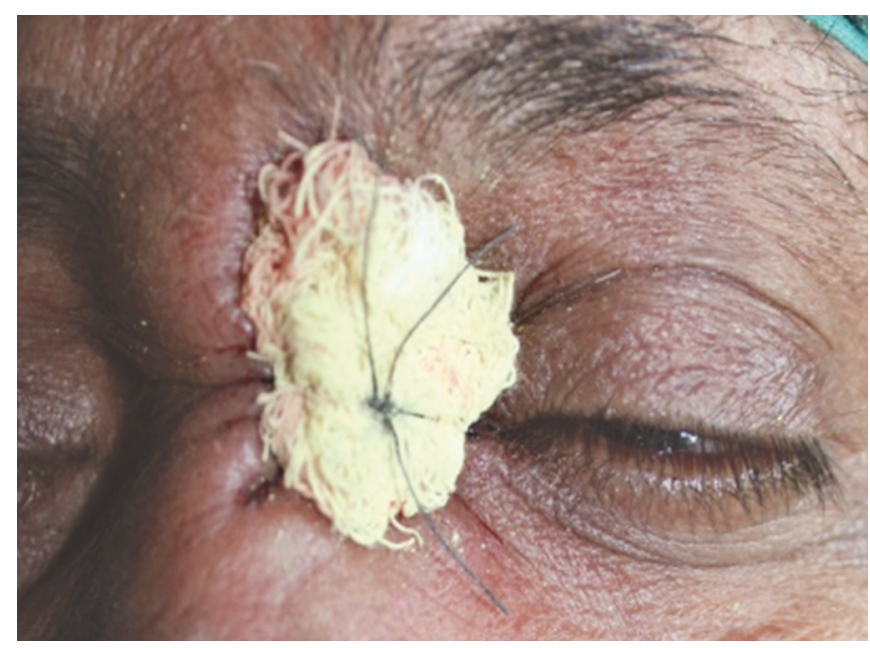

Fig. 7: Bolster dressing with BIPP paste

Numerous options available for of the medial canthal reconstruction including healing by secondary intention, full thickness skin grafts, and local or regional flaps. Small lesions $(<1.5 \mathrm{~cm})$ that do not involve upper or lower eyelid can heal by secondary intention, especially in older adults. When the wound is large $(>1.5 \mathrm{~cm})$, secondary healing and wound contracture may lead to ectropion formation. 7 Skin grafting can provide esthetically satisfactory outcomes provided that the patient and defect are thoroughly examined preoperatively. Superficial defects up to $2 \mathrm{~cm}$ can be repaired using skin graft. In our case, we decided to go for skin grafting, as defect was superficial, periosteum was intact in the recipient site, and any local flap would have created another visible scar on forehead and distorted adjacent tissue. Skin graft can be harvested from upper and lower eyelid, retro auricular, supraclavicular, and preauricular region. We opted for preauricular region, as the patient was old with enough lax skin and wrinkles on face. Skin graft was defatted to increase the uptake of the graft at the recipient site. After removal of bolster dressing at 10 days, there was good uptake of the graft.

\section{Conclusion}

Reconstruction of medial canthal region is a complex process due to the shape and the complex anatomy of the area. Skin graft is useful technique in large superficial defects involving the medial canthus with good cosmesis and minimum postoperative complications.

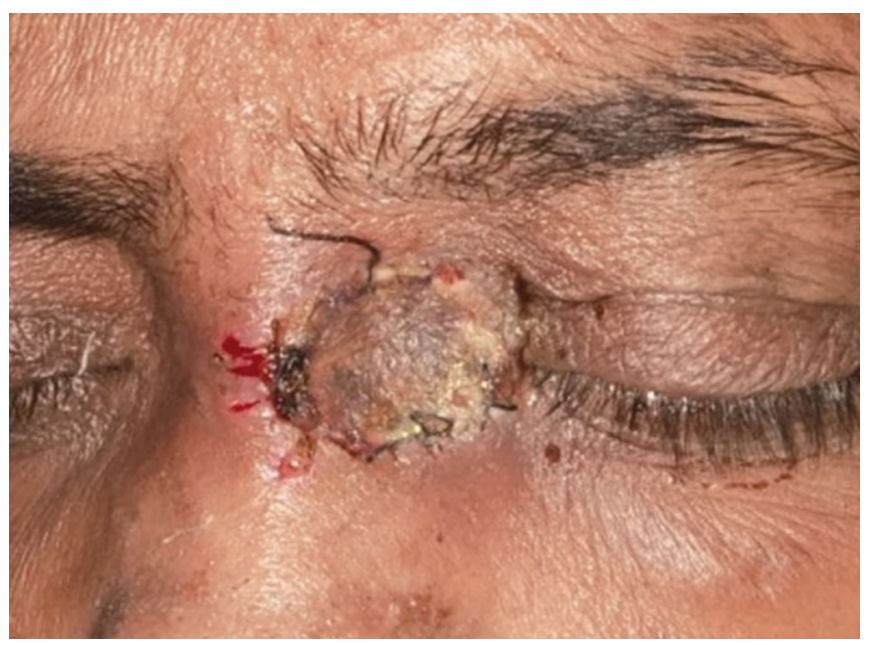

Fig. 8: Good uptake of the graft on day 10

\section{References}

1. Tilli CMLJ, Van Steensel MAM, Krekels GAM, et al. Molecular aetiology and pathogenesis of basal cell carcinoma. Br J Dermatol 2005;152(6):1108-1124. DOI: 10.1111/j.1365-2133.2005. 06587.x.

2. Cases T, Mikhail GR, Nims LP, et al. Metastatic Basal Cell Carcinoma. 2015; (March 1971).

3. Rubin Al, Chen EH. Basal-cell carcinoma. N Engl J Med 2005;353(21):2262-2269. DOI: 10.1056/NEJMra044151.

4. bingham1982.pdf.

5. Scrivener Y, Grosshans E, Cribier B. Clinical and laboratory Investigations variations of basal cell carcinomas according to gender, age, location and histopathological subtype. British Journal of Dermatology 2002;147:41-47.

6. Lykoudis EG, Lykoudis GE, Alexiou GA. "' Pickaxe"' double flap: a useful '" Tool"' for reconstruction of deep large medial canthal defects 5 -year experience and brief literature review. Aesthetic Plast Surg 2015;39(3):410-413. DOI: 10.1007/s00266-015-0462-3.

7. jelks2002.pdf.

8. Bichakjian CK, Olencki T, Aasi SZ, et al. Basal cell skin cancer, clinical practice guidelines in oncology. J Natl Compr Canc Netw 2016;14(5):574-597. DOI: 10.6004/jnccn.2016.0065.

9. Stewart CM, Norris JH. Reconstruction of extensive medial canthal defects using a single $\mathrm{V}-\mathrm{Y}$, island pedicle flap pedicle flap. Orbit 2018;37(5):331-334. DOI: 10.1080/01676830.2017. 1423344.

10. Kim JH, Kim JM, Park JW, et al. Reconstruction of the medial canthus using an ipsilateral paramedian forehead flap. Arch Plast Surg 2013;40(6):742-747. DOI: 10.5999/aps.2013. 40.6.742. 